\title{
Assessing Energy Transition Scenarios for Islands through Network Reliability and Power Flow Analysis
}

\author{
Essam. K. Hussain \\ PR. Thies \\ College of Engineering, Mathematics and Physical Sciences \\ University of Exeter \\ Penryn, UK
}

\begin{abstract}
This paper presents a methodology for the reliability and power flow assessments of island/off grid power networks for situations of scarce data and information. This could be a useful tool to help decision makers replacing fossil fuel with renewable energy sources for the off grid/ Island power networks. The aim of the paper is to present and apply a general methodology, informing the decision making towards sustainable island communities. Ushant Island, a small French island, is considered as a case study. The assessment of the current power network status and the reliability analysis reliability are presented. The grid performance parameters are further compared for conventional diesel generator operation and renewable energy generation scenarios to emphasis the advantages of replacing the ordinary diesel units with renewable energy sources in terms of system reliability and network future structure plan. It provides recommendations for the system structure.
\end{abstract}

Index Terms-- Islanding, Load flow, Microgrids, Power system planning, Power system reliability.

\section{INTRODUCTION}

Many islands and remote communities have no connection to wider electricity distribution systems and are dependent on imported energy supplies, typically fossil fuels. The energy systems that isolated communities depend on tend to be less reliable, more expensive and have more associated greenhouse gas (GHG) emissions than mainland grid systems. The European Commission's White Paper on Renewable Energy Sources and the United Nations Conference on Islands and Small Island States highlight the need to provide the islands with an outline for the development in renewable energies[1].

Moving from fossil fuel to renewable energy and thus increasing the penetration of renewable energy generation in an island's power grid is a research topic of interest. The study of the present electricity situation in some African island states is presented in [2], highlighting the critical lack of electricity in some islands due to political instability and high cost of diesel. Renewable energy could form part of the solution. IRES-KB is a user interactive software and one of early tools to estimate the amount of renewable energy sources required supply an off grid network. The number of seasons per year and a combination of certain set of resources and energy demands are the input of the software [3]. The RenewIslands methodology based on mapping an island's energy requirements and resources and subsequent modelling of the grid is presented in [4]. In [5] different scenarios of renewable energy sources combination are considered for seven villages in India. It considered the reliability, total system cost and cost of energy for integrating the renewable energy sources. The reliability study is based on the Energy Index Ratio (EIR) and Expected Energy Not Supplied (EENS). The Caribbean island of Montserrat is considered as a case study to transfer from diesel to $100 \%$ renewable energy [6]. The steps to transfer from diesel based generation to Geothermal and $\mathrm{PV}$ is presented outlining the benefits of replacing the diesel units in term of cost [6]. Finding the optimum location of the renewable energy source depending on the minimum total losses in the network and the impact of disconnecting the renewable energy sources, fault and unbalanced voltage are presented in [7].

As can be seen, the literature is focused on how to transition from diesel based generation to renewable energy by studying the energy demand and the combination of available renewable energy sources. There has been less attention on the current power network of the island grid and weather they need to be expanded or modified. However, this is a crucial step in the analysis and energy transisiton, as the grid infrastructure (or lack thereof) will be critical to inform the approach and feasibility of potential energy transition scenarios. Often this is due to a lack of publicly available information regarding the grid infrastructure. This paper offers a pragmatic approach to derive some of the required power network information and presents a network analysis method that informs the assessment of energy transition scenarios. Additionally, it presents a developed methodology based on the available data and information, comprised of available power network data, component and hardware data sheets.

A situation with limited or restricted access to data is a common occurrence for island and isolated communities, 
where the full documentation and detailed energy usage profiles may not be readily accessible. The focus of the analysis is to perform a relative comparison between the current power networks, supplied by traditional power generation units, and a sustainable energy supply through renewable generation units. This relative comparison is valid, even if the absolute parameter values have some uncertainties. The Ushant Island power network is analysed as an example to demonstrate the methodology and to outline the assessment of replacing the traditional generator units with renewable energy sources. The essential parameters for the reliability and power follow analyses such as grid components/units parameters; load profile, renewable energy assessment and grid components reliability can be delivered by the power suppliers, estimated or assumed.

\section{USHANT ISLAND POWER NETWORK}

The French island of Ushant, off the coast of Brittany, is currently off-grid in terms of electrical energy and heating, thus heavily relies on expensive and $\mathrm{CO} 2$ emitting diesel generation to meet its energy requirements. The overall cost of generation through fossil fuels is currently over twice as high as the national average electricity cost of $€ 0.169 / \mathrm{kWh}(£ 0.149 / \mathrm{kWh})$ [8]. Due to the price volatility of fossil fuels, the generation cost is also subject to significant fluctuations over time leading to unpredictable future prices that may substantially raise the yearly expenditure on generation. Hence, Ushant is planning to shift away from fossil fuels towards more secure, sustainable and cheaper sources of energy. By diversifying the island's energy mix with a greater percentage of renewable energy (RE) generators, Ushant could exploit more of its natural energy sources that are available in the area. Despite the fact that renewable energy sources, like wind and solar, may follow general timely patterns, they are still intermittent and relatively unpredictable. Consequently, if more RE was planned to be installed on Ushant, it would be necessary to implement strategies to balance generation and demand, such as energy storage. An optimization and energy management of renewable energy to replace the Ushant Island diesel generators with renewable energy sources is presented in [9]. The Ushant island power network is modelled as a single large load, without consideration of the Ushant current grid and reliability/capacity of individual load nodes. The local network operator SDEF manages the power network of Ushant Island.
The Ushant grid consists of two main networks; a high voltage network, $5.5 \mathrm{kV}$, and a low voltage network/distributed network. The schematic diagram of the high voltage network Ushant Island network is shown in Fig. 1. The present generation portfolio comprises four off 1.2MW Diesel Generators and a 0.5MW Diesel Generator. Additionally, a 0.045MWp Solar PV array has been installed on the roof of the Sports Hall rooftop since 2014. Hence, the total peak generating capacity is $5.345 \mathrm{MWp}$. The power demand over the year in 2016 is shown in Fig. 2 [8]. There is significant seasonal variation in the electrical demand on the island. Electricity consumption is much higher during the winter as the majority of buildings on the Islands rely on electrical heating [10].

The Ushant Island power network schematic diagram and the total load power are the only accessible data sets. There is little information about the load at each load node and the parameters of the power network. However, this information is necessary for the reliability and power flow analysis assessment of the island's grid to understand the capacity and ability of the grid to enable any energy transition plans. Two engineering parameters have to be identified / estimated; power cable parameters (type of cable, length, diameter) in order to derive the equivalent inductance, resistance and capacity of the cable and the load at each node in the network regarding power supply and demand.

\section{A. Cable Parameters}

By using PlotDigitizer software [11] one can estimate the cable length between load nodes. Basically, the geographical map is loaded into the software and the user selects the coordination system limit ( $\mathrm{X}$ and $\mathrm{Y}$ ) according to the geographical map scale.

The software scales each point (pixel) on the map. Therefore, the length of the cable can be estimated by the cable route. Depending on the length, core materials and the size of the cable the equivalent inductance, resistance and the capacitor can then be inferred. Subsequently, the cable parameters can be identified as in (1) to (3) [12].

$$
c=2.24 \times S I C / \log (D / d) \times L
$$

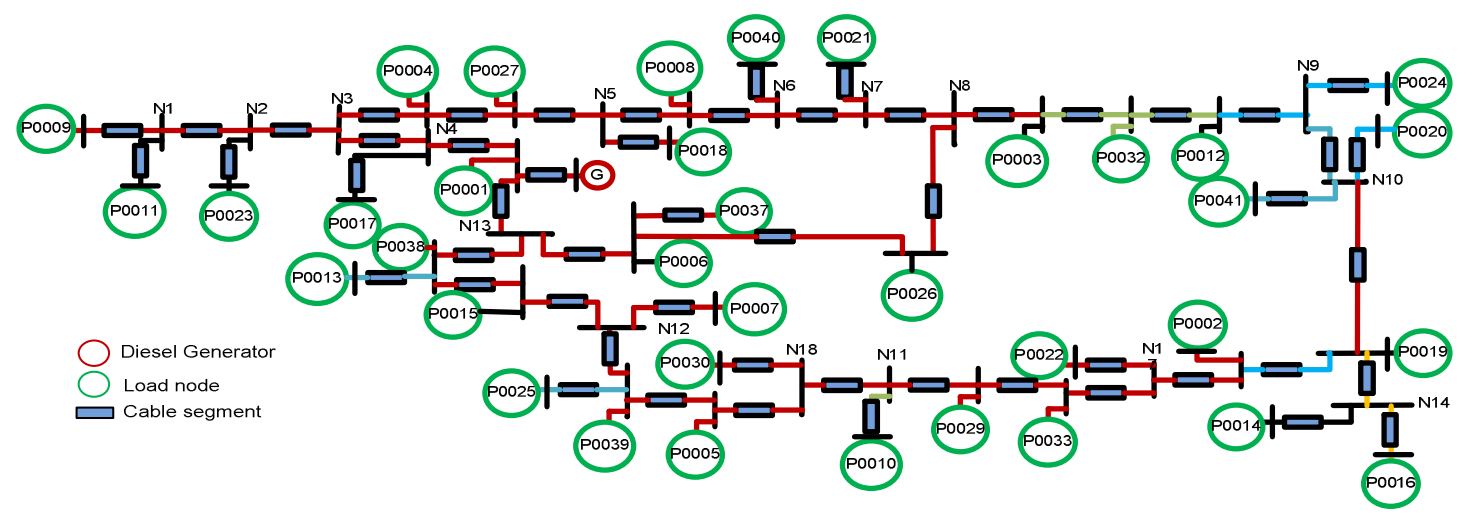

Figure 1. Ushant Island's power network 


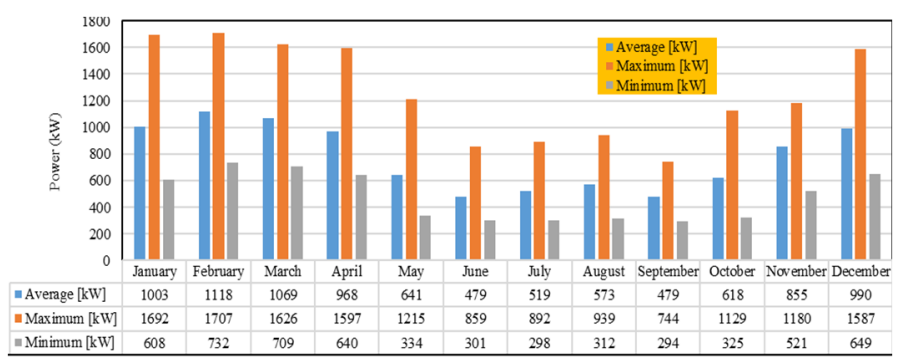

Figure 2. Ushant Island average, maximum and minimum power demands over a year (2016)

$$
\begin{gathered}
L_{c}=0.3043 \frac{\left(0.0153+0.1404 \times \log _{10} \frac{\sqrt[3]{A \times B \times C}}{d}\right)}{10^{6}} \times K \times L \\
R=\rho \frac{L}{a}
\end{gathered}
$$

Where, $C$ is the total capacitance of the cable. SIC is the dielectric constant of the cable insulation and $D$ is the diameter over the insulation. $\boldsymbol{d}$ is diameter of the conductor, $L$ is the length of the cable, $\boldsymbol{L} C$ is the cable Inductance (in $\mathrm{mH}$ ) and $\boldsymbol{A}$, $B, C$ are spaces among the cable cores in. $\mathrm{K}$ is the installation correction factor, $R$ is the cable resistance, $\boldsymbol{\rho}$ is the cable core resistivity and $\boldsymbol{a}$ is the cable core area.

From the cable manufacturer's data sheets, for a $5.5 \mathrm{kV}$ cable, the typical insulation thickness is $2.25 \mathrm{~mm}$. A crosslinked polyethylene (XLPE) type cable is assumed which has a low dielectric constant of 2.3. The highest correction factor is chosen (1.5) [12]. These specifications are chosen to emulate the worst conditions. The core martial of the cable is Aluminum. Based on this information, the cable resistance, inductor and capacitor are estimated.

\section{B. Load at each node}

The load can be estimated by establishing a catchment area for each node and counting the number of houses/ building in this area, using a reference model for each load demand. The catchment area is drawn based on the nearest building to the node. The base model of the house is chosen to be a small house $\left(70 \mathrm{~m}^{2}\right)$. The total number of buildings is 1,105 , which is more than the number of people living on the island permanently (850 [13]), suggesting that about $2 / 3$ rd of the buildings are likely to be holiday homes and related to tourism. Once the system parameters of the cable and power network are established, a Simulink model, using Matlab Simulink, is developed to study the power flow of the network. Once this essential network data is established, the power network can be assessed regarding reliability and power flow.

\section{POWER FLOW ANALYSIS OF THE USHANT ISLAND POWER NETWORK}

It is useful to study the Ushant power network without introducing the renewable energy sources to the network. This helps to understand the capacity usage of the network and the possibility of the grid to accept new renewable energy without modifying the infrastructure of the power network. This analysis can then inform the selection of the most suitable locations for renewable energy deployments from a power network perspective. It indicates the potential rated power of renewable energy generation and location, which the existing network can support without requiring network upgrade investments. The peak energy demand recorded throughout the six years of available data is $2.08 \mathrm{MW}$, in March 2013 [8]. The peak demand of $2.08 \mathrm{MW}$ is employed for the power flow analysis of the Ushant network. The power factor of the load node is assumed to be 0.7 which is normally the lowest power factor of the grid [14]. Based on this peak load, the load demand at each node is calculated as the percentage of the number of buildings at each node as shown in Fig. 3 (the displayed values are placed on the real load location), where the maximum load demand occurs at the city center $(190 \mathrm{~kW})$.

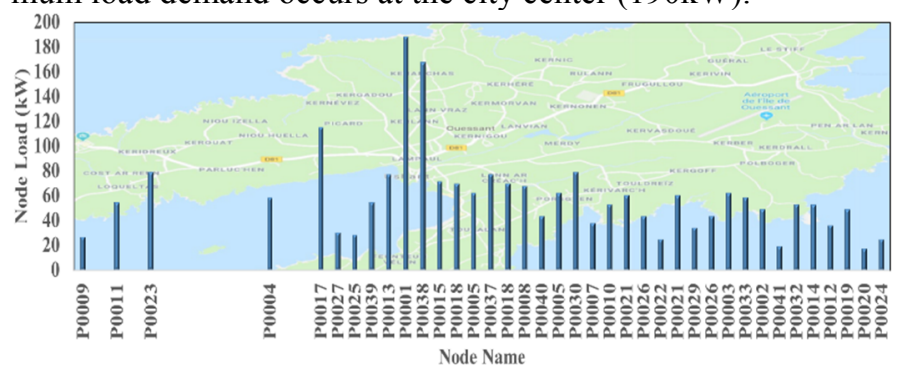

Figure 3. Power load at each node for the peak load demand (March 2013)

To analyze the cable current capacity under the highest load demand. Fig. 4 shows the percentage of cable current capacity usage under the highest load demand (2.08MW). The highest cable capacity usage is at the city centre (58\%). It seems that the Ushant power network is capable of adding more loads and generation units. The cable capacity analysis indicated that as much as $2.7 \mathrm{MVA}(1.87 \mathrm{MW}$ at $0.7 \mathrm{pf})$ could be added as power generation capacity.

To study the effect of introducing the renewable energy sources to the Ushant Island, different scenarios of the types and combination of the renewable energy sources are presented in [13]. Scenario 7 in [13] is selected as a case study where it has the highest power generation during the winter and has three power sources, which increases the system reliability. In this scenario, three power generation units, Sabella D10 tidal turbine, extensive solar installations $(20 \%$ of rooftops) and an $800 \mathrm{~kW}$ wind turbine are considered. The location of the tidal turbine is selected to be in the south west of the island. However, the location of the wind turbine is not mentioned. Two cases of the wind turbine locations are suggested in this paper as shown in Fig. 5 where these locations have higher voltage drop (1.019\%-1.5\%), higher failure 0.08370.0974 failure/year) rate and the nearest load does not have the lower cable capacity usage (2\%-3\%). According to the recorded data for the Ushant Island in 2016 [13] the output power at the maximum load is shown in Table 1. It is assumed that there is a battery storage system, which is capable of storing the surplus generation energy and injecting the shortage in energy demand. 


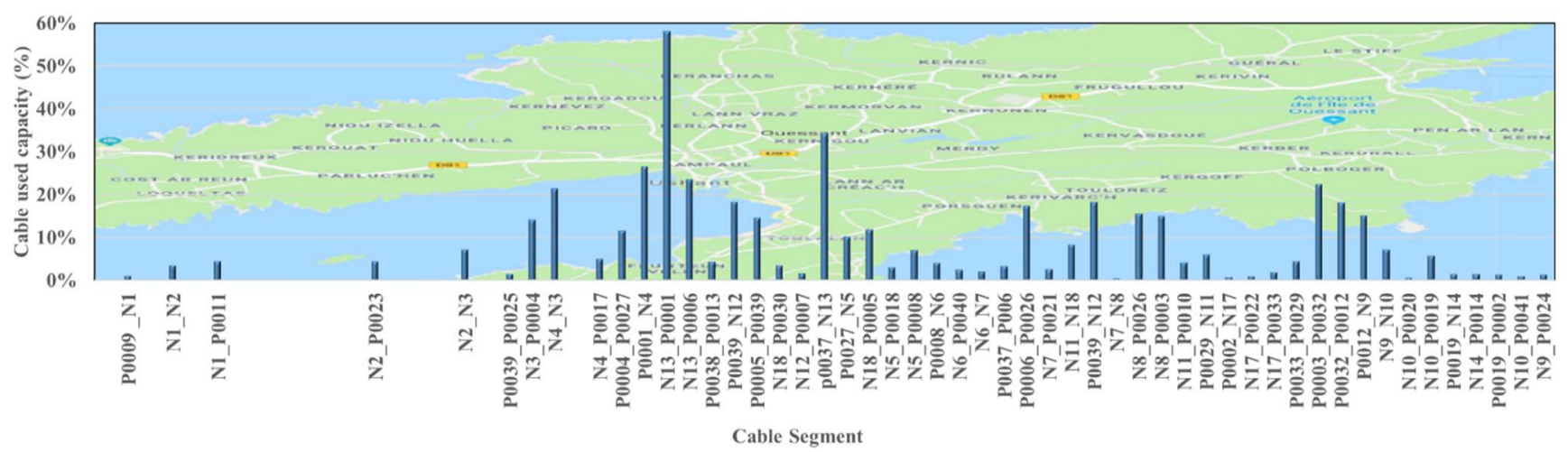

Figure 4. Cable capacity usage

TABLE 1. POWER DEMAND AND GENERATION AT THE MAXIMUM LOAD

\begin{tabular}{|c|c|c|c|c|c|}
\hline $\begin{array}{c}\text { Renewable } \\
\text { sources }\end{array}$ & $\begin{array}{c}\text { Solar } \\
(\mathbf{2 0 \%})\end{array}$ & Wind & Tidal & Total & $\begin{array}{c}\text { Load de- } \\
\text { mand }\end{array}$ \\
\hline Output power & $0 \mathrm{~kW}$ & $810 \mathrm{~kW}$ & $2.7 \mathrm{~kW}$ & $813 \mathrm{~kW}$ & $1707 \mathrm{~kW}$ \\
\hline
\end{tabular}

Under the maximum load demand, the cable capacity usage is no more than $40 \%$ at the city centre. The rest of the cable capacity usage is small (1\% to $20 \%)$ as shown in Fig. 6 . There is little different between the two scenarios of the wind turbine locations in terms of the cable capacity usage. The wind turbine location in scenario 2 seems to have slightly power cable

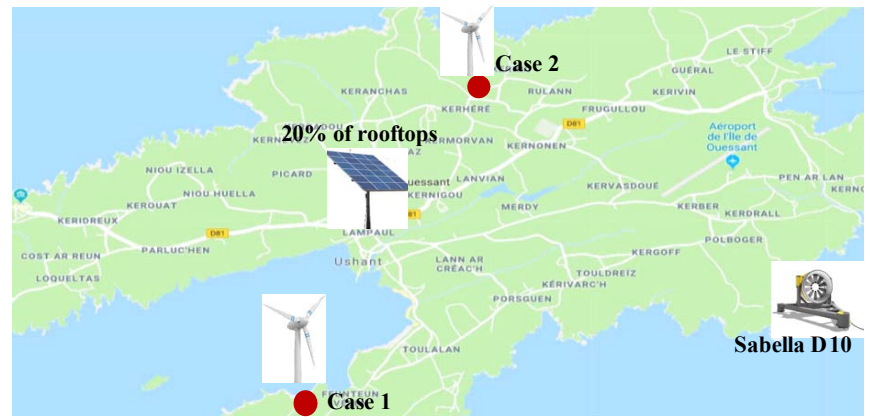

Figure 5. Cases for the wind turbine locations capacity usage where the maximum is $(52 \%)$.

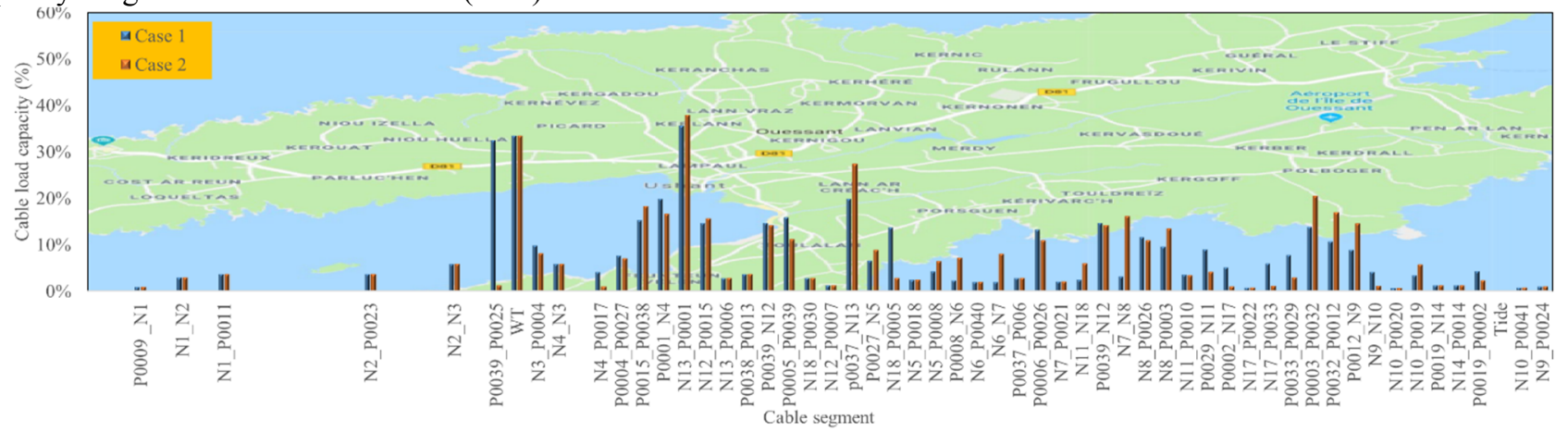

Figure 6. Cable capacity usage under two cases of the WT locations

\section{RELIABILITY ANALYSIS OF THE USHANT ISLAND POWER NETWORK}

A reliability analysis of the current Ushant network gives an indication regarding the failure rate/year of each node, for example, how often in the year there is no power at a specific load node. Moreover, it provides a general estimate of the power network reliability.

For Ushant Island, there is no available/recorded data of the cables, transformers, generator and circuit breaker failure rates. Published papers and literature can be used to as an estimated of the failure rate of the most common network elements. An overview of typical failure rates data for power network components is shown in Table 2 . The average data are derived and summarized from [15-23].
TABLE 2. FAILURE RATE OF THE MAIN POWER NETWORK [15-23]

\begin{tabular}{|l|c|l|c|}
\hline Element & Failure rate & Element & Failure rate \\
\hline Cable & $0.0386 / \mathrm{km}$ & AC generator & 0.0877 \\
\hline Transformer & 0.0526 & Power inverter & 0.0433 \\
\hline Circuit Breaker & 0.0131 & & \\
\hline
\end{tabular}

All the failure rates of the mechanical system of the renewable energy sources such as turbine, diesel generator mechanical parts and gearbox are not considered in this paper, as the focus lies om the electrical infrastructure and network, rather than on the mechanical system. In this reliability study, the reliability block diagram is built employing Reliability Block Diagram Analysis (RBD) software (ReliaSoft) for each load node, modelling the AC generators, power cables, a transformer at the node and a circuit breaker connecting the load to the grid. An example of a load node reliability block diagram is shown in 
Fig. 7 for load node P0002. At least two out of four diesel generators should be operational together to supply the load demand.

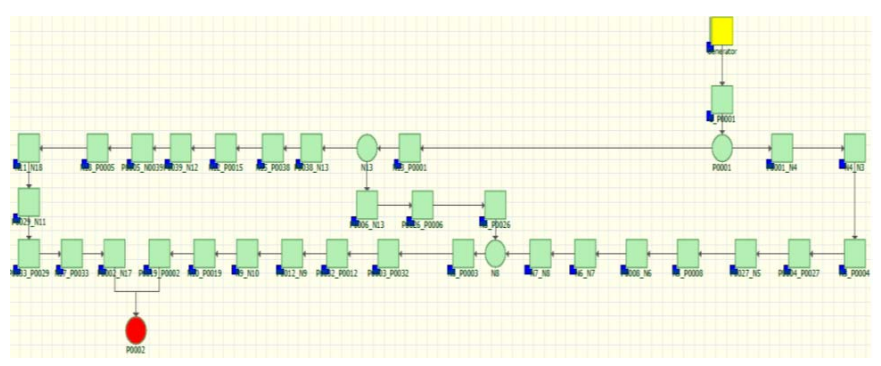

Figure 7. Load node P0002 reliability block diagram

It is interesting to compare the failure rate of the Ushant grid under the diesel generators and the renewable energy sources. Fig. 8 shows the failure rate of the load node under renewable energy sources compared with the diesel network operation. As can be seen from Fig. 8, the failure rates of the load nodes are decreased according to the nearest to the renewable energy sources.

The renewable energy sources reduce the failure rate of the load nodes by $1 \%$ to $47 \%$. It seems that the failure rate of the load node at the city centre reduced significantly (up to $37 \%$ ). This is because the PV that is mainly at the city centre have high reliability compared to the $\mathrm{AC}$ generator.

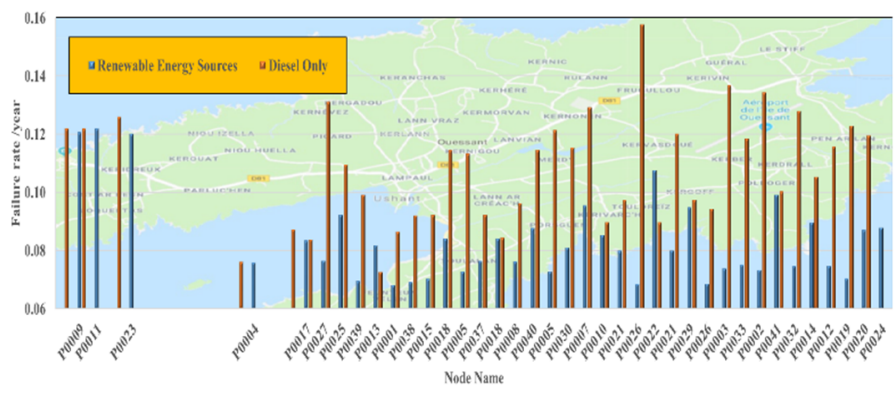

Figure 8. Load node failure rate under diesel and renewable energy sources

\section{CONCLUSION}

In this paper, a topology for the reliability and power flow analysis is presented based on a proposed methodology to find/estimate the required data of the power network for the analysis. The two main Ushant power network modes are considered and compared with each other. The first mode is the current power network and the second is replacing the diesel generators with a selected renewable energy sources. For the power network operated by diesel generators, the power network cables can support an additional average of $1.8 \mathrm{MW}$ load/power generation units and the failure rate of the load node is less than $0.13 /$ year. The load node at the city centre has a high cable capacity usage $58 \%$ and a lower failure rate of $<0.07 /$ year. By introducing renewable energy, the failure rate of the power network is decreased by $50 \%$. Furthermore, there is high energy generation from the renewable energy sources which needs a huge battery storage system and proper control to handle the power among the loads and renewable energy sources.

\section{REFERENCES}

[1] C. f. t. C. European Commission, "Energy for the future: renewable sources of energy, White Paper for a community strategy and action plan," COM, pp. 599, 1997.

[2] D. Surroop, and P. Raghoo, "Renewable energy to improve energy situation in African island states," Renewable and Sustainable Energy Reviews, vol. 88, pp. 176-183, 2018/05/01/, 2018.

[3] R. Ramakumar, I. Abouzahr, K. Krishnan, and K. Ashenayi, "Design scenarios for integrated renewable energy systems," IEEE Transactions on Energy Conversion, vol. 10, no. 4, pp. 736-746, 1995.

[4] N. Duić, G. Krajačić, and M. da Graça Carvalho, "RenewIslands methodology for sustainable energy and resource planning for islands," Renewable and Sustainable Energy Reviews, vol. 12, no. 4, pp. 10321062, 2008/05/01/, 2008.

[5] A. B. Kanase-Patil, R. P. Saini, and M. P. Sharma, "Integrated renewable energy systems for off grid rural electrification of remote area," Renewable Energy, vol. 35, no. 6, pp. 1342-1349, 2010/06/01/, 2010.

[6] B. Römer, K. Aldonza, Y. Julliard, and O. Lewis, "Planning 100\% renewable energy islands: the case of the Caribbean island of Montserrat," CIRED - Open Access Proceedings Journal, vol. 2017, no. 1, pp. 2488-2492, 2017.

[7] S. S. S. A. M. M. B. Narayanan, "Dynamic analysis of renewable energy systems and their impact on smart grid," in 16th NATIONAL POWER SYSTEMS CONFERENCE, India, 2010.

[8] EDF. "The EDF Open Data Platform on the Ponan Islands," https://opendata-iles-ponant.edf.fr/pages/home/.

[9] O. H. Mohammed, Y. Amirat, M. Benbouzid, S. Haddad, and G. Feld, "Optimal sizing and energy management of hybrid wind/tidal/PV power generation system for remote areas: Application to the Ouessant French Island." pp. 4205-4210.

[10] S. Consultants, "Etude de faisabilite d'une operation de maitrise de l'energie et de developpement des energies renouvelables sur les îles de Molene at Ouessant," Lyon, France, 2009.

[11] J. S. V. J. Ammirato, and W. Fairechio, Predicting lead sheath cable failures, p.^pp. 428.

[12] Y. Gill, "Development of an electrical cable replacement simulation model to aid with the management of aging underground electric cables," IEEE Electrical Insulation Magazine, vol. 27, no. 1, pp. 8, 2011.

[13] S. Z. Jon Hardwick, Helen C.M. Smith, Oscar Fitch-Roy, Jonathan Williams, Peter M. Connor, Senthilarasu Sundaram, Gregorio Iglesias, A Community Specific Assessment of Local Energy, Exeter University, UK, 2018.

[14] S. A. Papathanassiou, and F. Santjer, "Power-quality measurements in an autonomous island grid with high wind penetration," IEEE Transactions on Power Delivery, vol. 21, no. 1, pp. 218-224, 2006.

[15] AME, "Reliability and availability of wave energy devices," Advanced Mechanics \& Engineering, 1992

[16] YARD, "Reliability of six wave power devices."

[17] SINTEF, Offshore Reliability Data Handbook, 5 ed., 1984.

[18] A. J. B. A. E. Green, Reliability Technology Wiley-Blackwell, 1978.

[19] X. J. Chengke Zhou, Zeyang Tang, Wei Jiang , Babakalli Alkali, Wenjun, and a. J. Y. Zhou, "STATISTICAL APPROACHES FOR ANALYSIS OF FAILURE DATA IN POWER CABLES," in CIGRE 2012, PARIS, 2012.

[20] A. S. A. Hassan M. Nemati, Sławomir Nowaczyk, "Reliability Evaluation of Underground Power Cables with Probabilistic Models," in Int'l Conf0. Data Mining, DMIN'15 Las Vegas, Nevada, USA, 2015.

[21] D. J. A. Jey K. JEYAPALAN, "MAKING REMAINING LIFE PREDICTIONS FOR POWER CABLES USING RELIABILITY ANALYSES," in International Conference on Power Insulated Cables, Jicable'07, Versailles , France, 2007.

[22] V. J. Ammirato, J. Silecchia, and W. Fairechio, "Predicting lead sheath cable failures." pp. 428-431.

[23] Y. Gill, "Development of an electrical cable replacement simulation model to aid with the management of aging underground electric cables," IEEE Electrical Insulation Magazine, vol. 27, no. 1, pp. 31-37, 2011. 